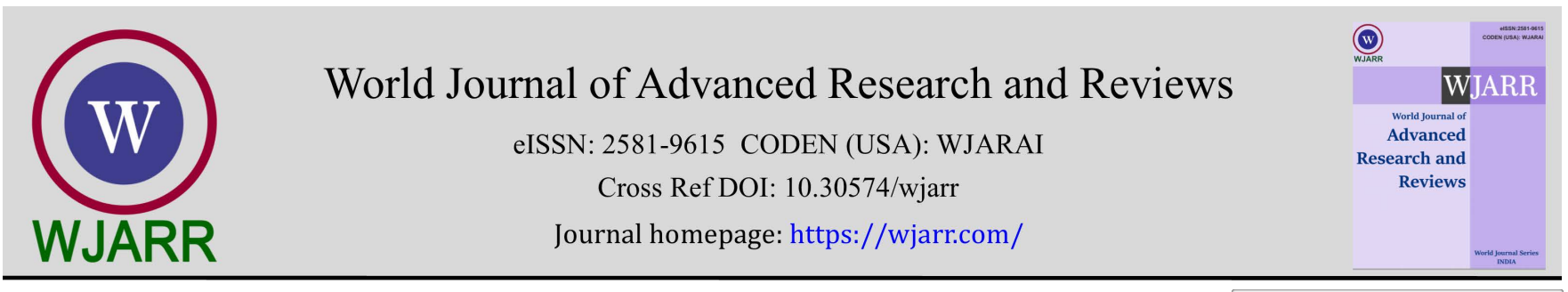

(CASE REPORT)

Check for updates

\title{
A case of anencephaly in an Unbooked Primipara diagnosed at 35 weeks gestation
}

Awopola Ibiebelem Jumbo * and Esther Ijeoma Nonye-Enyidah

Department of Obstetrics and Gynaecology, Rivers State University Teaching Hospital, Port Harcourt, Nigeria.

World Journal of Advanced Research and Reviews, 2021, 12(02), 555-558

Publication history: Received on 16 October 2021; revised on 24 November 2021; accepted on 26 November 2021

Article DOI: https://doi.org/10.30574/wjarr.2021.12.2.0623

\begin{abstract}
Background: Anencephaly is a rare but lethal congenital anomaly of the neural tube. Ideally, the diagnosis is made early in pregnancy and the pregnancy is usually terminated. This is to prevent avoidable complications during pregnancy and childbirth as well as the accompanying psychological trauma from late intrauterine foetal death or death during the neonatal period.
\end{abstract}

Objective: To report a case of anencephaly in an unbooked primipara at 35 weeks gestation.

Methods: The case note of the patient and how she was managed were reviewed. A relevant review of the literature on the subject was also done.

Case report: Mrs A.N was a 22year old unbooked G3P1+1 who was referred to the Rivers State University Teaching Hospital (RSUTH) on the $4^{\text {th }}$ of September, 2021 with a three-day history of bleeding per vaginam and an ultrasound scan report of an absent cranium and club foot at 35weeks gestation. She resided in a rural area and was on herbal medication in the index pregnancy. She did not receive routine antenatal medications and had no family history of congenital malformations. She had an induction of labour at presentation and delivered a severely asphyxiated male anencephalic baby weighing $2.0 \mathrm{~kg}$. The baby died 9 minutes after delivery.

Conclusion: Anencephaly is a lethal anomaly that is associated with folic acid deficiency. Despite available diagnostic tools, most women in rural areas lack access to antenatal care and will have a late diagnosis and increased morbidity. Thus, there is a need to improve access to antenatal care for women in rural communities, as well as supplement food with folic acid for women in the reproductive age group.

Keywords: Anencephaly; Congenital anomaly; Folic acid; Rural area

\section{Introduction}

Anencephaly is a lethal congenital anomaly of the central nervous system in which the brain and cranial vault are grossly underdeveloped [1]. It is due to the failure of the cranial end of the neural tube to close during the third and fourth week of embryonic development $[1,2]$.

Most cases of anencephaly are multifactorial and involve the interaction of multiple genes and environmental factors [2]. The specific genes involved are yet to be identified although genes involved in folate metabolism are believed to play a role [3]. The majority of the anencephalic pregnancies end in miscarriages or as stillbirths but some pregnancies may continue and the babies are born alive [4]. Almost $100 \%$ of anencephalic babies die in infancy [4,5]. The incidence of anencephaly at birth is 1 in 4859 [5]. Anencephalic pregnancy may be complicated with polyhydramnios, prolonged

${ }^{*}$ Corresponding author: Awopola Ibiebelem Jumbo

Department of Obstetrics and Gynaecology, Rivers State University Teaching Hospital, Port Harcourt, Nigeria.

Copyright (C) 2021 Author(s) retain the copyright of this article. This article is published under the terms of the Creative Commons Attribution Liscense 4.0. 
pregnancies, abnormal lie or presentation, traumatic injuries in labour and an increased risk of intervention in pregnancy [4].

Anencephaly could be suspected early in the second trimester with raised maternal alpha-fetoprotein [6], the diagnosis is confirmed with ultrasonography or amniocentesis [6]. The definitive management is to terminate the pregnancy as there is no treatment for anencephaly inutero [4,5]. Continuing the pregnancy leads to increased complications and psychological trauma for the mother [4,5]. This is a case of anencephaly who presented at 35weeks gestation.

\section{Case report}

Mrs. A.N was a 22year old unbooked G3P1+1 (alive) with secondary education who was referred to the RSUTH on the $4^{\text {th }}$ of September, 2021 from a Primary Health Centre with a three-day history of mild bleeding per vaginam and an ultrasound scan report of an absent cranium and club foot at 35 weeks gestation. The pregnancy was supervised by a quack in a rural setting. She was on herbal liquid preparations in pregnancy but did not receive routine antenatal medications. There was no history of rash or fever earlier in pregnancy. Her previous confinement was supervised at the same place but was normal. She was not diabetic, hypertensive or epileptic. Examination findings were normal. Results of full blood count, random blood sugar, hepatitis B surface antigen, retroviral screening and venereal disease research laboratory test were normal. Labour was induced with 50ug vaginal misoprostol 6hourly, and she received three doses. She had a vaginal delivery on the $6^{\text {th }}$ of September, 2021 at $0100 \mathrm{hrs}$. The outcome was a severely asphyxiated male baby weighing $2.0 \mathrm{~kg}$ who died 9 minutes after birth. The baby had anencephaly, cleft lip and palate, clubfoot, no eyes, and low set ears.

The mother was counselled to have antenatal care and to avoid unprescribed medications in a subsequent pregnancy. She was discharged home on routine haematinics. She was also seen in the postnatal clinic 6weeks later and further counselling on periconceptional folic acid and contraception was done.

\section{Images of the anencephalic neonate}
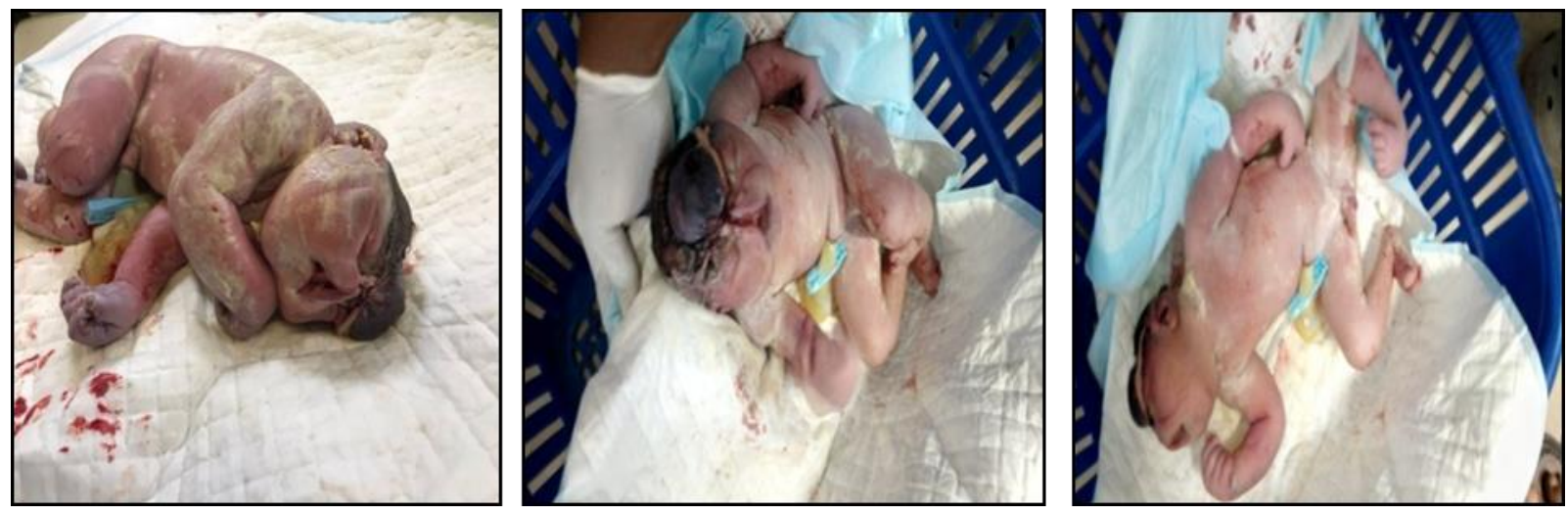

\section{Discussion}

Anencephaly is the most severe manifestation of neural tube defect and is incompatible with sustained life [2,5]. The risk factors for anencephaly include family history, obesity, poorly controlled pregestational diabetes, and folic acid deficiency. It also includes febrile illness in the early first trimester, exposure to pesticides, and medications such as anticonvulsants and antimetabolites [2,7]. The only identified risk factors in Mrs A.N were lack of folic acid intake in pregnancy and use of herbal medication which composition could not be ascertained.

Anencephalic pregnancy is associated with a higher risk of polyhydramnios, prolonged pregnancy, malpresentation, increased risk of intervention and genital tract injuries [4]. It is also associated with an increased psychological trauma for the woman. To reduce these complications early diagnosis is essential. Anencephaly can be detected early in the second trimester by screening for maternal serum alpha-fetoprotein (MSAFP) especially in high-risk women [6]. The diagnosis is confirmed with ultrasonography or amniocentesis (for alpha-fetoprotein and acetylcholinesterase) [6]. Anencephaly cannot be treated inutero therefore termination of pregnancy is the only option to prevent the birth of a child with anencephaly following prenatal diagnosis [4,5]. Mrs A.N presented late and thus could not benefit from early diagnosis and pregnancy termination. 
Since Anencephaly is a lethal condition, measures to prolong the pregnancy is not necessary. This will worsen the emotional stress of carrying a congenitally malformed foetus, increase the complications of pregnancy as well as psychological trauma when the baby is born [4]. Mrs A.N has an induction of labour at presentation following adequate counselling.

Anencephaly is often an isolated birth defect [2], rarely it may be associated with other anomalies such as spinal bifida, cleft palate and clubbed foot and gastroschisis [8]. The baby had associated cleft lip and palate, no eyeballs and clubbed feet. The prognosis of an anencephalic baby born alive is poor as most of the babies die in the neonatal period as in this case [4].

The recurrence risk for neural tube defects (NTDs) is 2-5\% in a subsequent pregnancy [9]. Folic acid supplementation is the most important intervention to prevent anencephaly and other NTDs [10]. It is usually given at a high dose of 4$5 \mathrm{mg}$ starting from about three months before conception [10]. Mrs A.N will benefit from periconceptional folic acid, prenatal screening and diagnosis. Unfortunately, these services are not readily accessible to women in rural areas. Other measures to prevent anencephaly include stopping antifolates and other harmful medications before pregnancy, good glycaemic control, and weight reduction.

\section{Conclusion}

Anencephaly is a lethal anomaly. It is associated with folic acid deficiency and could be prevented with routine folic acid supplementation. Early diagnosis is also possible with screening for MSAFP and ultrasonography. However, most women in rural areas in Sub-Saharan Africa lack access to these facilities and thus will continue to suffer late diagnosis. Therefore, there is a need to improve access to antenatal care for women in rural communities, and fortify nutrients with folic acid for women in the reproductive age group.

\section{Compliance with ethical standards}

\section{Acknowledgements}

We wish to express our profound gratitude to everybody who participated in the management of this patient.

\section{Disclosure of conflict of interest}

The authors have no conflict of interest in this case report.

\section{Statement of informed consent}

As per university standard guidelines, participant consent and ethical approval have been collected and preserved by the authors.

\section{References}

[1] Moussaoui KE, Bakkali SE, Ghrab I, Baidada A, Kharbach A. Anencephaly: Case report and literature review. J Gynecol Res Obstet. 2021; 7(1): 005-007.

[2] Munteanu O, Cîrstoiu MM, Filipoiu FM, Neamțu MN, Stavarache I, Georgescu TA, et al. The etiopathogenic and morphological spectrum of anencephaly: a comprehensive review of literature. Rom J MorpholEmbryol. 2020; 61(2):335-43.

[3] Kibar Z, Torban E, McDearmid JR, Reynolds A, Berghout J, Mathieu M. Mutations in VANGL1 associated with neural-tube defects. N Engl J Med. 2007; 356(14):1432-7.

[4] Ekmekci E, Gencdal S. What's Happening When the Pregnancies Are Not Terminated in Case of Anencephalic Fetuses? J Clin Med Res. 2019; 11(5): 332-36.

[5] Dickman H, Fletke K, Redfern RE. Prolonged unassisted survival in an infant with anencephaly. BMJ Case Rep. 2016.

[6] Palomaki GE, Bupp C, Gregg AR, et al. Laboratory screening and diagnosis of open neural tube defects, 2019 revision: a technical standard of the American College of Medical Genetics and Genomics (ACMG). Genet Med. 2020; 22: 462-474. 
World Journal of Advanced Research and Reviews, 2021, 12(02), 555-558

[7] Bonhotal S. Screening and Risk Factors for Anencephaly. J Nurse Pract. 2015; 11(3): 371-2.

[8] Gole RA, Meshram PM, Hattangdi SS. Anencephaly and its Associated Malformations. J Clin Diagn Res. 2014; 8(9): AC07-AC09.

[9] Moore L. Anencephaly. J Diagnostic Med Sonogr. 2010; 26(6): 286-9.

[10] Locksmith GJ, Duff P. Preventing neural tube defects: The importance of periconceptional folic acid supplements. Obstet Gynecol. 1998; 91(6): 1027-34. 